\title{
ON ANALYSIS AND CONTROL OF FINANCIAL RISKS AND A VIEW OF TURKISH AND EUROPEAN BANKS AND FINANCIAL MARKETS
}

\section{Hasan Eken *}

\section{Abstract}

In this paper, four main financial risks that banks get exposed to in functioning as intermediary institutions are analysed and decomposed into their components. After that the two components of these risks namely; volatility and sensitivity, are calculated for both Turkish and European Union commercial banks in aggregates. Volatility is the exogenous component of risk and hence it is out of control of banks. Volatility can partly be controlled by the governments. On the other hand sensitivity is calculated as using banks' balance sheet figures. Thus, it is under the control of banks and it can be managed by them.

\section{Introduction:}

A very basic definition of financial risk can be made as "the probability of facing losses due to both movements in financial indicators and positions held by entities on their balance sheets". Financial risks have effects on all economic units operating in the financial systems including individuals, financial firms and non-financial entities.

Individuals and non-financial entities are exposed to financial risks only as borrowers (the case of being short in a particular risk) or as lenders (the case of being long in a particular risk). That is to say that individuals and non-financial entities are affected by financial risks in a single way either as a borrower or as a lender.

* Dr., Lecturer in Banking and Finance, T.C. Kadir Has University, The Institute of Social Sciences 
On the other hand financial intermediaries, say banks, due to their natures of being intermediary institutions are involved in borrowing and lending activities simultaneously. Therefore, it is obvious that financial intermediaries are exposed to financial risks in two different passages named; lending passage and borrowing passage. Accordingly, their exposure to a particular risk is calculated as the sum of risk that is related to the amounts borrowed and lent by them. This type of risk is named risk born of financial intermediation. ${ }^{1}$

\section{Main Financial Risks:}

There are four main financial risks ${ }^{2}$ to be addressed; credit risk, interest rate risk, foreign exchange rate risk and liquidity risk. Credit risk is defined as the probability of the borrower to fail to pay back the amount lent to him or her. Interest rate risk can be defined as the probability of facing losses due to movements in interest rates. Foreign exchange rate risk is defined as the probability of losing money due to movements in exchange rates. Liquidity risk is defined as deficiency in liquid resources to meet the daily operations and other liquidity needs.

Table 1: The Two Dimensions of Financial Risks: Volatility and Sensitivity

\begin{tabular}{|c|c|c|c|c|}
\hline TOTAL RISK & $=$ & VOLATILITY & $\mathrm{X}$ & SENSITIVITY \\
\hline TOTAL RISK & $=$ & SYSTEMIC PART & $\mathrm{X}$ & $\begin{array}{l}\text { NON-SYSTEMIC } \\
\text { PART }\end{array}$ \\
\hline CREDIT RISK & $=$ & $\begin{array}{l}\text { VOLATILITY IN } \\
\text { DEFAULT }\end{array}$ & $\mathrm{X}$ & $\begin{array}{l}\text { AMOUNT OF } \\
\text { CREDITS }\end{array}$ \\
\hline $\begin{array}{l}\text { INTEREST } \\
\text { RATE RISK }\end{array}$ & & $\begin{array}{l}\text { VOLATILITY IN } \\
\text { RATES }\end{array}$ & $\mathrm{X}$ & $\begin{array}{l}\text { INTEREST RATE } \\
\text { GAP }\end{array}$ \\
\hline F/X RISK & $=$ & $\begin{array}{l}\text { VOLATILITY IN } \\
\text { EXC.RATES }\end{array}$ & $\mathrm{x}$ & F/X GAP \\
\hline $\begin{array}{l}\text { LIQUIDITY } \\
\text { RISK }\end{array}$ & - & VOLATILITY IN M1 & $\mathrm{x}$ & LIQUIDITY GAP \\
\hline
\end{tabular}

From the definition of financial risks, it can be seen that all financial risks have two dimensions ${ }^{3}$ as shown at the above table. The first dimension named "volatility", is the macro economical part of the total risk and is represented as changes in macro economical financial indicators and/or markets. This first dimension; volatility, of total risk can be defined as the "systemic" part of the total risk. All entities facing a particular financial 
risk, should take this part of total risk as exogenous. In other words they have no control on this part of the total risk. The only body that has power to control this part of total risk is "the government". Thus, controlling and/or diminishing volatility in all macro economical indicators is thought to be the job of the governments.

The second dimension of financial risks is named "sensitivity". Sensitivity can be defined as short or long position held by entities on their financial tables affected by movements in financial indicators such as; interest rates, exchange rates and etc.. Since this part of total risk is the position held by entities, there is no doubt that they have power to control it. Therefore, sensitivity, which is thought to be a firm preference, can be dealt as the "non-systemic" part of total risk.

With this in mind, controlling sensitivity is not a duty of governments. From the government's perspective, sensitivity is exogenous. However, due to the special roles of some entities such as; the role of banks in financial markets ${ }^{6}$, governments feel responsible for controlling them and their sensitivities to a particular volatility or risk in order to control the total financial risks that those entities are exposed to.

As can be seen from the above table, volatility, which is assumed to be a macro economical issue, can be measured in the form of movements in interest rates, exchange rates and etc.. Sensitivity, which is assumed to be a firm preference, can be measured in the form of positions held by banks with regard to interest sensitive balance sheet items, foreign currency assets and liabilities, total amount of credit expanded and the difference between liquid assets and liquid liabilities.

\section{Present Situation in Turkey}

\subsection{Volatility}

Over the last two decades, the main source of volatility in Turkey has been inflation which is reflected in the form of movements or volatility in interest rates, exchange rates and etc. With the help of economic programmes developed in cooperation with International Monetary Fund, the last few governments have successfully decreased inflation figures that have long been the main source of volatility. However, even in a low inflation economy, volatility can still be at dangerous levels. It is important 
to underline that volatility is not the high level of variables but it is the high level of movements with deep swings in variables.

With this sense, bringing down inflation, the main source of volatility, does not mean that volatility is reduced to an acceptable level as well. A sharp decline in volatility will be witnessed when confidence in markets grow. Thus, the present Turkish government is suggested to continue to support and apply the policies helped them to pull down inflation figures over the last 1.5 years. That will eventually help them to grow the public's confidence in the programmes applied.

In most economies; low public confidence in the government's policies and/or markets, political instability, changes in policies, international developments (a shock increase in petrol, a war etc.), can easily result in deep swings in interest rates, exchange rates and etc. which increases the volatility in markets. Therefore, even in a low inflation climate volatility can still be a threat to the economic entities.

\section{Table 2: Volatility in Turkish Markets}

\begin{tabular}{|lcccc|}
\hline Volatility In(\%) & $\underline{\mathbf{2 0 0 0}}$ & $\underline{\underline{2001}}$ & $\underline{\underline{2002}}$ & $\underline{\mathbf{2 0 0 3}}$ \\
Inflation & 8.8 & 16.5 & 7.0 & 4.2 \\
Default Ratio & NA & NA & NA & NA \\
Interest Rates & 59.7 & 22.9 & 10.1 & 21.0 \\
Exchange rates & 6.8 & 21.7 & 9.6 & 7.4 \\
Money Supply & 15.5 & 16.8 & 13.9 & 14.2 \\
\hline
\end{tabular}

\section{Data were obtained from the web site of TCMB and TBB}

As can be seen from the above table, volatility, measured as standard deviations, in some macro economical issues, declined ${ }^{7}$ over the period 2000-2003. However, still there seems to be a high level of volatility in interest rates. That is probably due to the fact that, despite declining inflation rates, a decline with the same pace was not achieved in interest rates and therefore real rates remained at a very high level. This probably causes rates having a high volatility figure in comparison with the other macro economical indicators. 


\subsection{Sensitivity}

A firm can easily control its sensitivity to movements in interest rates or exchange rates and etc.. Therefore the management of a firm's sensitivity to a particular risk is not a duty of the government at all. It is the job or the preference of the firm itself.

However, the control and supervision of sensitivities of financial institutions (particularly banks) are thought to be a crucial duty of the governments. The governments set certain limitations ${ }^{8}$ on the sensitivities of financial firms to movements in interest rates, exchange rates and etc.. By doing this, it is believed that it helps to attain financial stability.

The recent legislation in Turkey ${ }^{9}$ obligated banks to establish efficient risk management departments and risk management systems in order to manage and control all the risks that they are exposed to. However, there is no evidence that banks have successfully established their systems and there is little evidence that banks have developed a risk management culture throughout their organisations, except for improvements in banks' reports to regulators.

The table below shows that Turkish banks reduced their sensitivities to exchange rate risk and liquidity risk over the period December $2000-$ September 2003. The increase in total credit expanded is nominal and it includes the effects of inflation as well. Unfortunately the data for interest rate risk is unavailable.

\section{Table 3: Sensitivity of Banks in Turkey}

\begin{tabular}{|lllll|}
\hline $\begin{array}{l}\text { Banks' Sensitivity } \\
\text { (Tril. TL) }\end{array}$ & Dec. 2000 & Dec.2001 & Dec. 2002 & Sept. 2003 \\
$\begin{array}{l}\text { Interest Rate Risk } \\
\text { RSA - RSL }\end{array}$ & NA & NA & NA & NA \\
\hline $\begin{array}{l}\text { Exchange Rate Risk } \\
\text { (F/X Position) }\end{array}$ & $(11622)$ & $(15645)$ & $(8646)$ & $(9997)$ \\
\hline $\begin{array}{l}\text { Credit Risk } \\
\text { (Total Credit) }\end{array}$ & 29181 & 36299 & 36630 & 61576 \\
\hline $\begin{array}{l}\text { Liquidity Risk } \\
\text { (Liquidity Gap) }\end{array}$ & $(15811)$ & $(70382)$ & $(59988)$ & $(7408)$ \\
\hline
\end{tabular}

- Data were obtained from the web site of TCMB and TBB 


\section{Present Situation in European Union}

\subsection{Volatility}

The volatility figures calculated for European Union are much lower than the same figures calculated for Turkey. As mentioned earlier the main source of volatility is considered to be high inflation figures in Turkey whereas low inflation figures result in low volatility figures in European Union. However, inflation is not the only cause for high volatility figures. Even in low inflationary environments, volatility in other macro economical variables can still be at high levels.

Volatility in inflation is almost insignificant in European Union. However, volatility figures measured in interest rates and euro/dollar parity are very high in comparison with low inflation figures. This is thought to be a result of decisively falling interest rates for volatility in interest rates. On the other hand volatility in euro/dollar parity is considered to be a result of weak euro until 2001 and strong euro against dollar over the last two years. Over this period euro/dollar parity moved between 0,80 and 1,28.

In terms of volatility figures, except for movements in rates and the euro/dollar parity, European Union seems to be a much safer arena in comparison with Turkey. However, despite the fact that volatility figures are at high levels for parity and rates, the way parity and rates were moving during the period being analysed were very much decisive in the same direction. That means the rates and parity were not swinging around a level but they were rather either increasing or decreasing decisively towards the same direction.

\section{Table 4: Volatility in European Union Markets}

\begin{tabular}{|lcccc|}
\hline Volatility In $(\boldsymbol{\%})$ & $\mathbf{2 0 0 0}$ & $\mathbf{2 0 0 1}$ & $\mathbf{2 0 0 2}$ & $\mathbf{2 0 0 3}$ \\
Inflation & 0,74 & 0,78 & 0,63 & 0,56 \\
Default Ratio & NA & NA & NA & NA \\
Interest Rates & 9,3 & 13,9 & 11,2 & 7,4 \\
Exchange Rates $(€ / \$)$ & 4,69 & 2,59 & 6,24 & 4,84 \\
Money Supply & 0,68 & 2,08 & 2,97 & 2,86 \\
\hline
\end{tabular}

Data were obtained from the web site of European Central Bank (ECB) 


\subsection{Sensitivity}

The table below shows that banks of European Union reduced have steady levels of sensitivities to changes in exchange rates, liquidity rates and changes credit default ratio over the period December 2000 - September 2003. Data for interest rate risk is unavailable.

In comparison with the same data for Turkish banks, European Union banks did not radically changed their sensitivities to particular risk over the period of analysis. However, changes in the Turkish banks' sensitivities were very sharp which implies that they change their position based on the movements in the markets as well as their expectations about the future developments in volatilities. These types of activities eventually increase their total level of risk.

\section{Table 5: Sensitivity of Banks in European Union}

\begin{tabular}{|lllll|}
\hline $\begin{array}{l}\text { Banks' Sensitivity (Tril. } \\
\text { TL) }\end{array}$ & $\underline{\text { Dec. 2000 }}$ & $\underline{\text { Dec.2001 }}$ & $\underline{\text { Dec. 2002 }}$ & Sept. 2003 \\
$\begin{array}{l}\text { Interest Rate Risk } \\
\text { RSA - RSL }\end{array}$ & NA & NA & NA & NA \\
\hline $\begin{array}{l}\text { Exchange Rate Risk } \\
\text { (F/X Position) }\end{array}$ & 1941 & 2025 & 1924,3 & 1647,5 \\
\hline $\begin{array}{l}\text { Credit Risk } \\
\text { (Total Credit) }\end{array}$ & 15598 & 16623 & 17565 & 19413 \\
\hline $\begin{array}{l}\text { Liquidity Risk } \\
\text { (Liquidity Gap) }\end{array}$ & 5530 & 5904 & 5997 & 6522 \\
\hline
\end{tabular}

Data were obtained from the web site of European Central Bank (ECB)

5. Managing and controlling volatility is assumed to be the job of the government.

Since the control of volatility is associated with the successful application of macro economical policies, it goes beyond the scope of this paper. Therefore, macro economical policies necessary for controlling volatility is left to macro economists.

\section{Managing sensitivity is assumed to be duty of entities.}

In an environment where volatility is low, still there will be a potential source of financial instability named "sensitivity". Even though 
governments could well reduce volatility, if sensitivity remains at high levels, still there will be a potential threat to firms in facing unanticipated losses. This will eventually hurt stability of the financial system. The more entities hurt the more severe effects will be witnessed.

Governments are responsible for controlling volatility; the systemic part of the total risk. The non-systemic part of total risk, named sensitivity, is not a duty of governments. It is indeed a job to be done by entities (individuals, financial firms and non-financial firms). An economic unit is free to choose a particular level of sensitivity to a certain risk, depending on its preference and/or risk aversion. A risk averse unit will tend to keep a high level of sensitivity on its balance sheet whereas a risk prone economic unit will tend to keep a low level of sensitivity on its financial tables.

However, in every country and in Turkey, governments control and supervise financial markets in general and banks in particular. The reason for this is that even though a government is successful in managing and controlling volatility, banks and other financial firms may choose high levels of sensitivity to financial risks which may eventually push them in troubles and as a result push financial markets into an unstable circumstance.

Therefore, governments' role becomes very crucial in terms of regulating financial entities. Determining the upper and lower limits on the levels of sensitivities to a particular risk that banks and other firms routinely hold on their balance sheets is a widely accepted way of supervision throughout the world.

Another issue is that governments target to help banks and other financial institutions to develop their own risk management culture in order to learn how to live with financial risks ${ }^{10}$. In Turkey, the related legislation has been effective since the year 2000 but there is no solid evidence that banks have developed their risk management cultures. Instead they have focused on reporting their levels of sensitivities to certain risks to the regulators. At present, it seems that reporting to the regulators is Turkish banks' main understanding of risk management. Thus, it becomes crucial that regulators spend more effort on educating banks in terms of risk management as well as reporting. To do that, the assistance of academics and professional risk consultants should be attained. 
Moreover, controlling banks and other financial firms and encouraging them to establish their own risk management systems and develop their own risk management cultures might help governments to achieve market stability partially. A complete stability, however, can be achieved when all non-financial firms also establish their own risk management systems and develop their own risk management cultures throughout their organisations. Thus, governments should encourage all financial and non-financial firms in the whole system to establish their own risk management systems and develop their own risk management cultures.

All these suggestions are of long term. In the very short term period, the most effective solution in Turkey is to encourage all financial and nonfinancial entities to diminish their sensitivities to certain financial risks so that their earnings are free of those risks.

\section{Conclusion: The Micro Economical Duties of the Financial Firms and the Regulators}

In general, banks in European Union seem to have already made their way in the area of risk management as well as operating in a safer and more stabile financial market. On the other hand, risk management is a new path for Turkish banks and the markets they operate in is very volatile that increase the total risk. Therefore, the following suggestions made are more for Turkish banks and authorities:

1- Financial entities should establish their own efficient risk management systems.

2- Financial entities should develop their own risk management cultures throughout their organisations as training their top managers as well as other employees.

3- The regulators should broaden their perspective so that they focus on risk management capabilities of financial entities as well.

4- The ongoing system of reporting to the regulators should be carefully analysed and the shortcomings of the reporting system should be rectified.

5- The regulators should encourage their employees so that their risk management and risk control talents are developed to the international standards.

6- A risk management based performance measurement system should be developed by the regulators. 
7- Analyses on risk pricing and funds transfer pricing should routinely be performed by financial institutions.

8- A Deposit Insurance System should be developed at international standards.

9- The government should retrieve from all financial markets.

10- Non-financial economic units should also be encouraged in terms of learning how to live with financial risks in a safe way.

\section{Endnotes}

${ }^{1}$ See Sinkey (1989)

${ }^{2}$ Market risk is a combination of two or more of these four financial risks.

${ }^{3}$ See Bessis (1998)

${ }^{4}$ Volatility is measured as the standard deviation from the mean. See for example;

Bessis (1998)

${ }^{5}$ Sensitivity is calculated as the part of risk coherent to the balance sheets of the entities. See for example; Sinkey (1989), Eken (1992).

${ }^{6}$ See Basel Commitee web site for a set of regulations (Basel II) suggested to regulators.

${ }^{7}$ This reduction in volatility should continue in order to improve public confidence.

${ }^{8}$ Governments legislation on the regulations of financial markets and particularly of banking industry is developed based on the Basel Committee's publications and suggestions.

${ }^{9}$ Banking Act No: 4389.

${ }^{10}$ In line with the Basel Committee, governments first introduced strict regulations, nowadays, besides these regulations, developing risk management talents of financial entities is also within their scope.

\section{References}

1- $\quad$ Baker, J.V., October 1978, Asset-Liability Management, Part 5: A Model of ALM Policy, Banking, V.70, P. 82-88.

2- Basel II: International Convergence of Capital Measurement and Capital Standards: a Revised Framework, BIS Web Site.

3- Bessis, J., 1998, Risk Management in Banking, First Edition, John Wiley and Sons, West Sussex, England. 
4- Bierwag, G.O. and Kaufman, G.G., 1977, Coping with the Risk of Interest Rate Fluctuations: A Note, Journal of Business, V.50, P.364-370.

5- Bierwag, G.O., Kaufman, G.G. and Toevs, A., 1983, Immunization Strategies for Funding Multiple Liabilities, Journal of Financial and Quantitative Analysis, V.18, N.1, P.113-124.

6- Binder, B.F., December 1980, Asset/Liability Management Part 2: Management and Control of Rate Sensitivity, Magazine of Bank Administration, V.56, P.31-35.

7- Eken, M.H., 1992, Asset/Liability Management (ALM) in Commercial Banks: Models, Tools, Applications, A Comparative Case Study: The U.K. and Turkey, Unpublished Master Thesis, The University of Exeter, U.K..

8- Eken, M.H., Oct. 1992, Bankalarda Aktif-Pasif Yönetimi,Bankacılar, No:10, P. 48-51.

9- Eken, M.H., 1994, Enflasyonun Bankacılık Üzerine Etkilerinin Risk ve Karlılık Açısından Değerlendirilmesi, Türkiye Bankalar Birliği, Yayın No: 187.

10- Glavin, W.M., 1982, Asset-Liability Management: A Handbook for Commercial Banks, Bank Administration Institute, Rolling Meadows, Illinois, U.S.A.

11- Van Greuning, H. and Bratanovic, S.B., 2000, Analysizn Banking Risk; A Framework for Assessing Corporate Governance and Financial Risk Management, The World Bank, Washington D.C.

12- Hempel, G.H., Coleman, A.B. and Simonson, D.G., 1990, Bank Management: Text and Cases, Third Edition, John Wiley and Sons Inc., U.S.A.

13- Kaufman, G.G., Summer 1984, Measuring and Managing Interest Rate Risk: A Primer, Economic Perspectives, Federal Reserve Bank of Chicago, P.16-29.

14- Simonson, D.G. and Hempel, G.H., Summer 1982, Improving Gap Management for Controlling Interest Rate Risk, Journal of Banking Research, P.109-115.

15- Sinkey, J.F.Jr., 1989, Commercial Bank Financial Management in the Financial Services Industry, Third Edition, MacMillan Publishing Company, U.S.A..

16- Stigum, M.L. and Branch, R.O., 1983, Managing Bank Assets and Liabilities; Strategies for Risk Control and Profit, First Edition, Dow Jones-Irwin, U.S.A.. 
17- Toevs, A.L., Spring 1983, Gap Management: Managing Interest Rate Risk in Banks and Thrifts, Economic Review, Federal Reserve Bank of San Francisco, P.20-35.

18- Toevs, A.L., 1986, Uses of Duration Analysis for the Control of Interest Rate Risk, in Platt, R.B., 1986, Controlling Interest Rate Risk: New Techniques and Applications for Money Management, First Edition, John Wiley and Sons, U.S.A.

19- Turkish Banking Act No:4389. 